\title{
Acute Myocardial Infarction in Progressively Elderly Patients. A Comparative Analysis of Immediate Results in Patients who Underwent Primary Percutaneous Coronary Intervention
}

\author{
Luiz Alberto Mattos, Alexandre Zago, Áurea Chaves, Ibraim Pinto, Luiz Tanajura, \\ Rodolfo Staico, Marinella Centemero, Fausto Feres, Galo Maldonado, Manoel Cano, Andréa Abizaid, \\ Alexandre Abizaid, A manda G.M.R. Sousa, J. Eduardo Sousa
}

São Paulo, SP - Brazil

\begin{abstract}
Objective - Analysis of the in-hospital results, in progressively elderly patients who undergo primary percutaneous coronary intervention (PCI) in the first 24 hours of AMI.

Methods - The patients were divided into three different age groups (60/69, 70/79, and $\geq 80$ years) and were treated from 7/95 until 12/99. The primary success rate and the occurrence of major clinical events were analyzed at the end of the in-hospital phase. Coronary stent implantation and abciximab use were employed at the intervencionist discretion.
\end{abstract}

Results - We analyzed 201 patients with age ranging from 60 to 93 years, who underwent primary PCI. Patients with ages above 70 were more often female $(p=.015)$. Those with ages above 80 were treated later with PCI $(p=.054)$, and all of them presented with total occlusion of the infarctrelated artery. Coronary stents were implanted in $30 \%$ of the patients. Procedural success was lower in $\geq 80$ year old patients $(p=.022)$, and the death rate was higher in $\geq 70$ years olds $(p=.019)$. Reinfarction and coronary bypass surgery were uncommon events. A trend occurred toward a higher combined incidence of major in-hospital events according to increased age $(p=.064)$.

Conclusion - Elderly patients ( $\geq 70$ years) presented with adverse clinical and angiographic profiles and patients $\geq 80$ years of age obtained reduced TIMI 3 flow success rates after primary $P T C A$, and those $\geq 70$ years had a higher death rate.

Key words: angioplasty, myocardial infarction, elderly

Instituto Dante Pazzanese de Cardiologia - São Paulo

Mailing address: Luiz Alberto Mattos - Av. Jandira 550/121 - São Paulo, SP 04080-003 - Brazil - E-mail: pivmattos@uol.com.br
Elderly patients are a progressively growing population, composing a high-risk subgroup for the occurrence of acute myocardial infarction (AMI). According to the American Heart Association, in the year 2000, the worldwide population above 70 years olds will be 21.1 millions, and the expectations for 2010,2020, and 2030 will be of geometric increase, with $27.3,35.7$, and 49.7 million elderly people, respectively. In the last eight years (1990/98), the population greater than 85 years of age, has increased more than $34 \%{ }^{1}$.

The potential of developing coronary heart disease in this increasing population of elderly people is remarkable. North American demographics from 1996 (American Heart Association Biostatistical Fact Sheets on Older Americans and Cardiovascular Diseases) indicate that $85 \%$ of the cardiovascular deaths occurred in patients greater than 65 years of age. In addition to this, $57 \%$ of the patients discharged after the occurrence of acute myocardial infarction (AMI), were above 65 years of age.

The occurrence of an AMI in patients older than 70, usually promotes higher death rates or other major complications related to this event ${ }^{1-5}$. Currently, thrombolytic therapy and percutaneous transluminal coronary angioplasty (PTCA) were the methods available for obtaining fast and early myocardial reperfusion ${ }^{2,6}$. However, few patients, less than $20 \%$ of the elderly patients with AMI, were selected to receive thrombolytic therapy in the first 24 hours of AMI onset ${ }^{1}$. The higher risk for the occurrence of a cerebral stroke causes caution to be taken with this therapeutic method when treating many elderly patients ${ }^{7-9}$. Otherwise, a recent analysis of subgroups of patients included in a large multinational AMI randomized trial did not show an effective reduction in death rates among patients older than 75 treated with thrombolytic therapy ${ }^{8}$.

Primary PTCA has many advantages over the administration of thrombolytic therapy ${ }^{10}$. Despite these, many elderly patients eager to be included in this therapeutic per- 
cutaneous revascularization method, did not receive that because of the clinical reluctance to include them ${ }^{1,11}$. The analysis of consecutive series of patients and randomized trials of the application of primary PTCA in the elderly population ${ }^{10,12,13}$ does not show a significant reduction in the death rate, with mortality increasing according to progressively higher ages, even after the reestablishment of normal coronary artery flow ${ }^{2}$.

The objective of this analysis is to verify the in-hospital results obtained in a recent consecutive series of patients treated with primary PTCA applied in the first hours of AMI in a progressively elderly population.

\section{Methods}

During the period from 7/1995 until 12/1999, we included for the purpose of this analysis, patients from both sexes, who were selected in a consecutive fashion for percutaneous coronary revascularization in the first 24 hours of AMI onset, either with primary balloon PTCA or primary coronary stent implantation. All patients had to fulfill the classic clinical inclusion criteria of AMI, which include chest pain, EKG changes, with ST-T segment elevation. The patients were divided in three different groups, according to the increasing in aging: 60/69, 70/79 and $\geq 80$ years old.

In the emergency room, patients were medicated with aspirin (200mg, PO), ticlopidine (500mg, PO, maintained during the first 30 days, in patients who underwent coronary stent implantation) and heparin (100 UI/kg IV), before the start of the procedure. Heparin was maintained for 24 to 48 hours after the procedure (1000 UI/hour) adjusted according to the APPT $(\geq 2.5 x$ of the normal value). The patients also received beta-blockers (metoprolol 15mg/IV) and ACE inhibitors (enalapril, 30mg PO/day), for patients with a left ventricular ejection fraction lower than $40 \%$.

The coronary angiography was performed with the Sones or Judkins techniques. The catheters that were applied had to be larger than 6 Fr, and the contrast media used were ionic. In the event of multivessel coronary heart disease, only the infarct-related vessel was treated.

Primary balloon PTCA was performed with standard catheters, keeping a final balloon/artery ratio of $1: 1$, to the mean reference diameter of the vessel treated. According to the interventionist discretion, intracoronary stents could be implanted, even as a primary procedure or in the event of a suboptimal result after balloon PTCA $(\%$ SD $>50 \%$ or severe coronary artery dissection). The final objective of the procedure was an optimal angiographic result, with the lowest estenose that could be achieved.

Patients selected for coronary stent implantation usually presented with vessel diameter $\geq 2.50$ or $\leq 4.50 \mathrm{~mm}$. All stents were implanted with higher pressure balloon assisted inflation $(\geq 12 \mathrm{~atm})$.

Intracoronary thrombolytics were not employed. According to the interventionist discretion, intravenous infusion of abciximab could be used, either in a planned fashion or as a rescue procedure (residual thrombus, flow disturbances, or slow flow).

The clinical events were monitored from hospital admission until discharge. We analyze the rate of TIMI 3 coronary flow reestablishment and the occurrence of major clinical events, which were emergency surgery, reinfarction, stroke, and death, or the combination of all these events.

All the data were collected in a specific database (Angiocor), with individual files for each patient, completed by the surgeons. The program applied was the D-BASE III plus.

The quantitative coronary angiography (QCA) was performed off line (CMS, Medis, Leiden, The Netherlands). The angiograms were analyzed at two different times, before and immediately after the percutaneous intervention. The mean reference diameter and the minimal luminal diameter of the vessel were used to calculate the percentage of coronary stenosis diameter.

Statistical analysis - The comparison was performed according to three different age groups. The categorical variables were expressed in absolute numbers and their percentage, and the continuous variables with their average and standard deviation.

The categorical variables were compared using the Pearson's chi-square test and the continuous by analysis of variance (ANOVA). To localize differences between the groups, we used the fractionated chi-square test for the categorical variables and Tukey's procedure for the continuous variables. The $\mathrm{p}$ values $<0.05$ were considered statistically significant.

\section{Results}

During this period of time, 201 patients with ages ranging from 60 to 93 years - underwent primary percutaneous coronary revascularization (PCI). According to the progressive aging, the absolute number of patients in each group diminished. The group of patients $60 / 69$ years old comprise $53 \%$ of the entire data, the $70 / 79$ years olds, $37 \%$ and the patients with ages greater than 80 years old, $10 \%$.

Table I exhibits the clinical profile according to the age division. As the ages increase, AMI occurred more frequently in women, mainly after 70 years of age $(\mathrm{p}=0.015)$. The elderly group ( $>80$ years) was treated with a greater length of time passing from pain onset until first balloon inflation $(p=0.054)$. An average of $25 \%$ of the patients had already suffered a previous MI, and $11 \%$ were in Killip class 3 or 4 at admission. However, these variables were not statistically significant.

The coronary angiography, performed before primary PTCA, showed a higher number of patients older than 80 years, with moderate reduction in left ventricular function ( $\mathrm{EF}<50 \%$ ), as was the progressive presence of severe multivessel coronary heart disease, but without a statistical difference (table II). Coronary stents were implanted in $30 \%$ of the patients, in a similar fashion 


\begin{tabular}{|c|c|c|c|c|}
\hline & $60-69$ & $70-79$ & $\geq 80$ years & $\mathrm{p}$ \\
\hline Number of patients & 107 & 74 & 20 & \\
\hline Mean age (years) & $64.8 \pm 2$ & $73.8 \pm 2$ & $85.2 \pm 2$ & \\
\hline Female gender* & $27(25 \%)$ & $33(45 \%)$ & $7(35 \%)$ & 0.025 \\
\hline Diabetes mellitus & $24(22 \%)$ & $24(32 \%)$ & $4(20 \%)$ & 0.262 \\
\hline Hypercholesterolemia & $15(14 \%)$ & $12(16 \%)$ & $5(25 \%)$ & 0.466 \\
\hline \multicolumn{5}{|l|}{ Previous events $=$} \\
\hline Cardiac surgery & $11(10 \%)$ & $10(13 \%)$ & $1(5 \%)$ & 0.529 \\
\hline AMI & $23(21 \%)$ & $16(22 \%)$ & $6(30 \%)$ & 0.690 \\
\hline $\begin{array}{l}\text { Mean delay: } \\
\text { pain/PTCA + }\end{array}$ & $\begin{array}{c}274 \pm \\
139 \min \end{array}$ & $\begin{array}{c}250 \pm \\
137 \min \end{array}$ & $\begin{array}{c}342 \pm \\
167 \mathrm{~min}\end{array}$ & 0.037 \\
\hline AMI location $=$ anterior & $49(46 \%)$ & $38(51 \%)$ & $14(70 \%)$ & 0.135 \\
\hline Killip class III/IV & $9(8 \%)$ & $11(15 \%)$ & $3(15 \%)$ & 0.354 \\
\hline
\end{tabular}

between the groups. Abciximab infusion was applied in $7 \%$ of patients them.

The PCI success (TIMI 3 flow) and the occurrence of major clinical events were different according to progressive aging (table III). The TIMI 3 flow reestablishment was significantly lower in patients older than 80 years ( 84 vs. $60 \%, p=0.022$ ). The in-hospital death also increased with age: $3.7 \%, 10.8 \%$, and $20 \%$, respectively $(\mathrm{p}=0.025)$. In the comparison between the groups, the mortality rate was significantly higher in the group of patients with ages between $70 / 79$ years $(p=0.019)$. The other major clinical events were rare, and the frequency of emergency surgery was nearly zero. Stroke occurred in only one patient, with age greater than 80 years. The combined clinical event rate showed a trend towards a higher occurrence of events, according to the increase in age $(\mathrm{p}=0.064)$.

The QCA measurements are displayed in table IV. All patients older than 80 years exhibited a total occlusion of the infarct-related vessel. Patients older than 70 years presented with coronary stenosis located in smaller vessels ( $\mathrm{p}=0.012)$, and those older than 80 years had a higher $\% \mathrm{SD}$ at the end of the $\mathrm{PCI}(\mathrm{p}=0.017)$.

\begin{tabular}{|c|c|c|c|c|}
\hline \multicolumn{5}{|c|}{$\begin{array}{l}\text { Table II - Angiographic profile from the } 201 \text { patients who } \\
\text { underwent percutaneous coronary revascularization during acute } \\
\text { myocardial infarction, according to progressive aging }\end{array}$} \\
\hline & $60-69$ & $70-79$ & $\geq 80$ years & $\mathrm{p}$ \\
\hline Number of patients & 107 & 74 & 20 & \\
\hline $\begin{array}{l}\text { Vessel treated - } \\
\text { left anterior } \\
\text { descending }\end{array}$ & $47(44 \%)$ & $37(50 \%)$ & $14(70 \%)$ & 0,541 \\
\hline right coronary & $44(41 \%)$ & $27(36 \%)$ & $5(25 \%)$ & \\
\hline left circumflex & $11(10 \%)$ & $7(9 \%)$ & $1(5 \%)$ & \\
\hline vein grats & $5(5 \%)$ & $3(5 \%)$ & 0 & \\
\hline Ejection fraction $\leq 50 \%$ & $45(42 \%)$ & $35(47 \%)$ & $13(65 \%)$ & 0,164 \\
\hline Multivessel disease & $47(44 \%)$ & $36(49 \%)$ & $13(65 \%)$ & 0,219 \\
\hline Proximal stenosis & $69(64 \%)$ & $50(67 \%)$ & $11(55 \%)$ & 0,579 \\
\hline
\end{tabular}

\section{Discussion}

We compared the in-hospital results after PCI in progressively elderly patients treated in the first 24 hours of AMI onset.

In 1992, we published a the first analysis of primary PTCA performed in 42 patients older than 70 years ${ }^{13}$. The success rate was $86 \%$ (TIMI flow 2 or 3 ), and the in-hospital death rate was $14.2 \%$.

The increase in elderly patients who underwent PCI was significant. To accomplish this task, 8 years were necessary to treat 42 patients, and in this contemporary analysis, 94 patients older than 70 years were treated in less than 5 years.

Now, in this more recent analysis, AMI occurred more frequently in female patients older than 70. Patients older than 80 years underwent PCI with higher delays; in vessels with compete occlusions and with significantly smaller size.

Since 1995, coronary stent implantation has been available, and its use is increasing geometrically, either in elective or AMI patients ${ }^{14}$. The results of coronary stent implantation during AMI was studied in the STENT PAMI randomized trial ${ }^{15}$. In this multinational study, primary coronary stent implantation significantly reduced the restenosis and the ischemia-driven TVR rates at the end of 6

\begin{tabular}{|c|c|c|c|c|}
\hline \multicolumn{5}{|c|}{$\begin{array}{l}\text { Table III - The success rate plus the occurrence of major in- } \\
\text { hospital clinical adverse events, according to progressive aging }\end{array}$} \\
\hline & $60-69$ & $70-79$ & $\geq 80$ years & $\mathrm{p}$ \\
\hline Number of patients & 107 & 74 & 20 & \\
\hline Stent usage & $38(36 \%)$ & $26(35 \%)$ & $5(25 \%)$ & 0,650 \\
\hline Abciximab infusion & $9(8 \%)$ & $4(5 \%)$ & $1(5 \%)$ & 0,690 \\
\hline Success (TIMI 3 flow) $*$ & $90(84 \%)$ & $62(84 \%)$ & $12(60 \%)$ & 0,032 \\
\hline Reinfarction & $3(2,8 \%)$ & $1(1,4 \%)$ & 0 & 0,630 \\
\hline Cardiac surgery & $1(1 \%)$ & 0 & 0 & 0,643 \\
\hline Stroke + & 0 & 0 & $1(5 \%)$ & 0,011 \\
\hline Death ++ & $4(3,7 \%)$ & $8(10,8 \%)$ & $4(20 \%)$ & 0,025 \\
\hline Combined events & $8(7,5 \%)$ & $9(12,1 \%)$ & $5(25 \%)$ & 0,064 \\
\hline \multicolumn{5}{|c|}{$\begin{array}{l}* 70-79 \text { years vs. } \geq 80 \text { years, } \mathrm{p}=0.022 .+70-79 \text { years vs. } \geq 80 \text { years, } \mathrm{p}=0.054 . \\
++70-79 \text { years vs. } \geq 80 \text { years, } \mathrm{p}=0.275 ; 60-69 \text { years vs. } \geq 70 \text { years, } \\
\mathrm{p}=0.019 .\end{array}$} \\
\hline
\end{tabular}

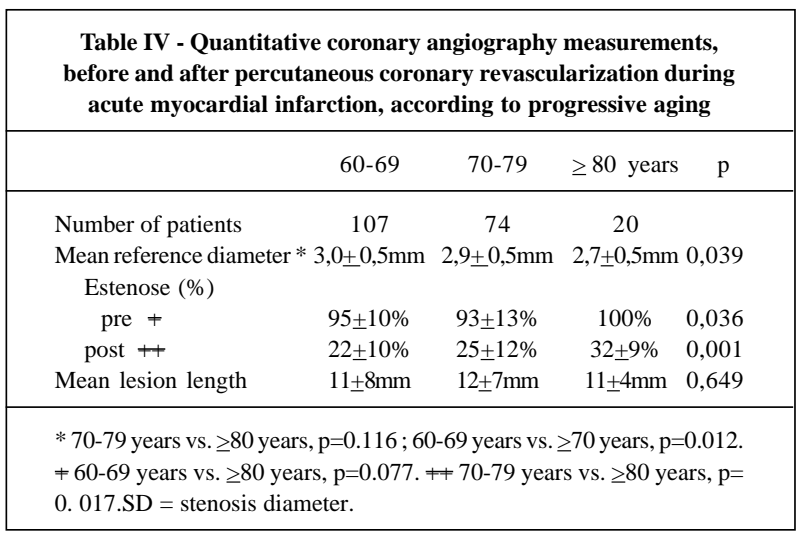


months. However, major complications related to AMI, such as death and reinfarction, were not modified.

In this more recent analysis, despite the introduction of new percutaneous devices such as stents or new pharmacological regimens such as abciximab, not much change has occurred in the success and major complications rates, compared with those demonstrated 5 years ago. Currently, the qualification of the success rate has been more strict (TIMI 3 flow), but similar success ( $84 \%$ ) has been obtained. As age increased, mortality did the same, with a $13 \%$ death rate after 70 years of age, which is also similar to the 1992 data. However, the use of coronary stents significantly reduced the reinfarction rate as was the need for emergency surgery ${ }^{13}$.

The reason for the low success rate observed in the group of patients older than 80 years may be disclosed by the analysis of the QCA measurements. This subset of older patients exhibited higher rates of total occlusions before PCI (TIMI 0 flow) associated with stenosis located in smaller vessels. Adding to this more adverse angiographic profile, these patients had a greater time delay until reperfusion was obtained. At the end of the procedure, they had the higher mean stenosis, with lower rates of TIMI 3 flow. As already demonstrated in larger consecutive series of primary PTCA, the presence of total occlusions compared with partial occlusions before PCI performance in the setting of AMI is a predictor of a lower success rate ${ }^{16}$.

The analysis of the major clinical events demonstrates that in-hospital death was progressively greater, according to the aging process. However, we did not observe a statistical difference when the two elderly groups were analyzed, 70/79 years versus $>80$, respectively.

The stroke rate was low, with only one case documented as an ischemic event. The absence of this adverse event in the other groups prevents a comparison between them.

The analysis of the GUSTO IIb randomized trail ${ }^{2}$ (rTPA vs. primary balloon PTCA in AMI) may help us in the explanation of these findings. Holmes and cols. demonstrated that according to age advancement, the occurrence of major clinical adverse events also gets higher. The authors emphasizes that despite the better results observed in elderly patients who undergo primary PTCA versus thrombolytic therapy, the percutaneous procedure did not modify the adverse clinical and angiographic profile related to the progressive aging process.

Similar conclusions were reported in the Cooperative Cardiovascular Project Registry ${ }^{1}$. This is a large nationwide database based on the Medicare assistance system, with more than 20,000 patients treated with ages greater than 65 years suffering AMI and treated within less than 12 hours of the onset of symptoms. The authors analyzed the in-hospital results and the end of 1 year outcome, comparing primary PTCA and thrombolytic therapy. From the initial cohort of patients that fulfill the inclusion criteria to receive both treatments, only $23.2 \%$ received thrombolytics and $2.5 \%$ underwent PTCA. The in-hospital deaths $(8.7 \%$ vs. $11.9 \%, \mathrm{p}=0.001)$ and deaths at 1 - year follow-up (14.4 vs. $17.6 \%, \mathrm{p}=0.001)$ were significantly reduced in patients who underwent primary PTCA. Despite this, the authors report that the benefit was marginal and lower than expected. Also, they emphasizes that still a small number of patients were treated with a reperfusion method, in fact only $25 \%$ from the whole cohort.

The use of new percutaneous and pharmacological regimens may benefit elderly patients. However, coronary stents and abciximab were applied in a small number of the patients, $30 \%$ and $5 \%$, respectively. This finding is in contrast with larger Brazilian percutaneous interventional data already published, which indicate stent usage in more than $70 \%$ of elective procedures and $45 \%$ of AMI interventions ${ }^{17,18}$. The analysis of the real impact of these new therapeutic methods requires a future large sample size.

The administration of IIb/IIIa block receptors in PCI during AMI is a more recent approach ${ }^{19}$. Reports of smaller randomized series have already indicated that an additional benefit occurs with their association, acting as a protector from distal coronary embolization, avoiding the plugging of the coronary microvasculature. The patients analyzed in these trials benefits with a greater recovery from left ventricular dysfunction, reduction in recurrent in-hospital ischemia and most important of all, obtain higher rates of TIMI 3 flow ${ }^{20-22}$. The association of coronary stents and IIb/ IIIa blockage are being tested in large multinational randomized studies that soon will be published ${ }^{22}$.

New thrombolytic regimens are also under study. However, the rate of cerebrovascular hemorrhagic stroke is still greater than those observed in primary PTCA, mainly in the elderly population. In recent published randomized trials, the rate of occurrence of hemorrhagic stroke was $1 \%$, ranging from 0.7 to $1.9 \%{ }^{7-9}$.

Conclusion - The progressively elderly patients who undergo PCI had an adverse clinical profile, with a significantly higher number of female patients ( $\geq 70$ years), a longer delay until successful reperfusion ( $\geq 80$ years), associated with a trend toward the presence of total occlusions (TIMI 0 ) before the procedure, in addition to the presence of stenosis located in smaller vessels ( $\geq 70$ years). The success rate (TIMI 3 flow) was lower in patients older than 80 years, with a progressive increase in the in-hospital death rate, mainly after 69 years of age. We also observed a trend toward a higher incidence of cumulative major clinical adverse events, according to progressive aging.

Determining the ideal therapeutic method for the elderly population suffering AMI still remains a challenge. In the near future, an optimized synergy of both percutaneous and pharmacological regimens may help reduce the morbidity and mortality event rates. 


\section{References}

1. Berger AK, Schulman KA, Gersh BJ, et al. Primary coronary angioplasty vs. thrombolysis for the management of acute myocardial infarction in elderly patients. JAMA 1999; 282: 341-8

2. Holmes DR, White HD, Pieper KS, Ellis SG, Califf RM, TopolEJ. Effect of age on outcome with primary angioplasty versus thrombolysis. J Am Coll Cardiol 1999; 33: 412-9.

3. Paul SD, O Gara PT, Mahjoub ZA. Geriatric patients with acute myocardial infarction: cardiac risk factors profiles, presentations, thrombolysis, coronary interventions and prognosis. Am Heart J 1996; 131: 710-5.

4. Weaver WD, Litwin PE, Martin JS, et al. Effect of age on use of thrombolytic therapy and mortality in acute myocardial infarction. J Am Coll Cardiol 1991; 18: 657-62.

5. White HD, Barbash GI, Califf RM, et al. Age and outcome with contemporary thrombolytic therapy: results from the GUSTO I trial. Circulation 1996; 94 1826-33.

6. Fibrinolytic Therapy Trialists (FTT) Collaborative Group. Indications for fibrinolytic therapy in suspected acute myocardial infarction: collaborative overview of early mortality and major morbidity results from all randomized trials of more than 1000 patients. Lancet 1994; 343: 311-22.

7. Assessment of the Safety and Efficacy of a New Thrombolytic (ASSENT-2) Investigators. Single bolus tenecteplase compared to with front-loaded alteplase in acute myocardial infarction: the ASSENT-2 double-blind randomized trial. Lancet 1999; 354: 716-22.

8. Thiemann DR, Coresh J, Schulman SP, et al. Lack of benefit for intravenous thrombolysis in patients with myocardial infarction who are older than 75 years. Circulation 2000; 101: 2239-46.

9. White HD. Future of reperfusion therapy for acute myocardial infarction. Lancet 1999; 354: 695-7

10. Weaver WD, Simes J, Betriu A, et al. Comparison of Primary Coronary Angioplasty and Intravenous Thrombolytic Therapy for Acute Myocardial Infartion. JA MA 1997; 278: 2093-8.

11. Stone GW, Grines CL, Browne KF, et al. Predictors of in-hospital and 6-month outcome after acute myocardial infarction in the reperfusion era. The Primary Angioplasty in Myocardial Infarction (PAMI) trial. J Am Coll Cardiol 1995; 25 : 370-7.
12. Mattos LA, Nunes G, Feres F, et al. Net benefit of primary PTCA for progressively elder patients: acute results and event free survival rate. Eur Heart J 1997; 18 : 275.

13. Mattos LA, Cano MC, Maldonado G, et al. Emprego da angioplastia coronária primária no infarto agudo do miocárdio em pacientes acima dos 70 anos. Arq Bras Cardiol 1992; 58: 181-7.

14. Sousa AGMR, Mattos LA, Moura Campos Neto C, et al. Intervenções coronárias percutâneas para revascularização no Brasil em 1996 e 1997, comparadas as do biênio 1992 e 1993. Relatório do Registro CENIC (Central Nacional de Intervenções Cardiovasculares). Arq Bras Cardiol 1998; 70: 423-30.

15. Grines CL, Cox D, Stone GW, et al. Coronary angioplasty with or without stent implantation for acute myocardial infarction. NEngl J Med 1999; 341: 1949-56.

16. O'Keefe JH, Bailey WL, Rutherford BD, Hartzler GO. Primary angioplasty for acute myocardial infarction in 1,000 consecutive patients - Results in an unselected population and high-risk subgroups. Am J Cardiol 1993; 72: 107G-15G.

17. Mattos LA, Pinto I, Abizaid A, et al. Efetividade e segurança imediata do implante de stents coronários. Resultados imediatos e tardios de 1.126 pacientes consecutivos tratados no biênio 1996/97. Arq Bras Cardiol 1999; 73: 23-9.

18. Mattos LA, Sousa AGMR, Moura Campos Neto C, Labrunie A, Alves CR, Saad J. Angioplastia coronária primária e implante de stents no infarto agudo do miocárdio: análise comparativa dos resultados hospitalares no registro CENIC/ SBHCI. Arq Bras Cardiol 1999; 73: 475-479.

19. Brener SJ, Barr LA, Burchenal MD, et al. Randomized, placebo-controlled trial of platelet glycoprotein IIb/IIIa blockade with primary angioplasty for acute myocardial infarction. Circulation 1998; 98: 734-41.

20. Neumann FJ, Blasini R, Schmitt C, et al. Effect of glycoprotein IIb/IIIa receptor blockade on recovery of coronary flow and left ventricular function after the placement of coronary-artery stents in acute myocardial infarction. Circulation 1998; 98: 2695-01

21. Montalescot G. The ADMIRAL Study: abciximab with PTCA and Stent in AMI 48th Annual Scientific Session of the American College of Cardiology, New Orleans, LO, USA, March 7, 1999.

22. Stone GW. The CADILLAC Study: In-hospital results. 72nd Scientific Sessions of the American Heart Association Meeting, Atlanta, GA, USA, November 8, 1999. 